January 2004

\title{
Validation of a food frequency questionnaire to assess macro and micro-nutrient intake among South Asians in the United Kingdom
}

Leena Sevak

London School of Hygiene and Tropical Medicine

Punam Mangtani

London School of Hygiene and Tropical Medicine

Valerie McCormack

London School of Hygiene and Tropical Medicine

Dee Bhakta

London School of Hygiene and Tropical Medicine

Tashmin Khamis

Aga Khan University, tashmin.khamis@aku.edu

See next page for additional authors

Follow this and additional works at: http://ecommons.aku.edu/eastafrica_fhs_fhs

Part of the Nutrition Commons

\section{Recommended Citation}

Sevak, L., Mangtani, P., McCormack, V., Bhakta, D., Khamis, T., Silva, I. S. (2004). Validation of a food frequency questionnaire to assess macro and micro-nutrient intake among South Asians in the United Kingdom. European Journal of Clinical Nutrition, 43(3), $160-168$.

Available at: http://ecommons.aku.edu/eastafrica_fhs_fhs/5 
Authors

Leena Sevak, Punam Mangtani, Valerie McCormack, Dee Bhakta, Tashmin Khamis, and Isabel dos Santos Silva 
Leena Sevak

Punam Mangtani

Valerie McCormack

Dee Bhakta

Tashmin Kassam-Khamis

Isabel dos Santos Silva

\section{Validation of a food frequency questionnaire to assess macro- and micro-nutrient intake among South Asians in the United Kingdom}

clues in South Asians. The FFQ was designed for a population-based case-control study of diet and breast cancer. Aims To validate a food frequency questionnaire (FFQ) to assess macro- and micronutrient intake among South Asians in the United Kingdom (UK). Methods A one-year long study of current diet was conducted using monthly telephone 24-hour recalls followed by administration of an interviewer-administered FFQ to ascertain usual diet during this period. General practices in the Thames and West Midlands regions, England were used to sequentially recruit 100 women from a larger random sample of South Asian migrants from general practitioners' patient lists participating as controls in a case-control study of diet and breast cancer. Results A total of 133 women were invited to achieve the final sample of 100 (76\% response rate). The proportion of individuals classified by the two dietary assessment methods into the same or adjacent quartiles was high ranging from $65 \%$ (vitamin A) to $96 \%$ (protein). Misclassification into opposite quar- tiles was very low (0\% to $5 \%)$, except for vitamin A (10\%). Energyadjusted Spearman correlation coefficients were reasonable for almost all nutrients being highest for protein (0.76), NSP $(0.71)$, folate (0.70) and cholesterol (0.69). Correction for within-person variation in monthly 24-hour recalls had little effect on the magnitude of the nutrient correlations between the FFQ and the 24-hour recalls. Calibration coefficients to correct relative risks for nutrient-disease associations were above 0.50 for most nutrients indicating that the degree of attenuation introduced by the FFQ would be acceptable. Conclusions This FFQ was specifically designed for South Asian women in the UK. Despite the diversity of diets, the FFQ had reasonable validity. The role of diet in breast cancer disease aetiology in this population is being assessed with this instrument. Sponsorship The study was supported by Cancer Research UK.

Key words food frequency questionnaire - diet assessment methods - validation - South Asians - migrants

\section{Introduction}

Diet plays an important role in the aetiology of many chronic diseases, such as coronary heart disease (CHD), non-insulin-dependent diabetes mellitus (NIDDM) and cancer. The South Asian population, with family roots in the Indian subcontinent regardless of place of birth, is one of the largest minority ethnic groups in the United Kingdom (UK), forming $2.7 \%$ of the UK population [1]. 
Risk of diseases such as CHD, NIDDM is high [2-6] and risk of cancer low $[7,8]$ in this population compared both to the native UK population and other migrant groups. It is, therefore, useful to investigate their disease experiences and dietary exposures for aetiological clues [9].

Within South Asia, diets are heterogeneous, with differences being mainly determined by region of origin (e. g. type of staples grown locally and available sources of fat), religious beliefs (e. g. Hindus do not eat beef and Muslims generally do not consume pork and alcohol), and Asian systems of medicine and folk understanding of health giving properties of various foods $[10,11]$. In the UK, the largest South Asian migrant groups are Gujarati Hindus, Punjabi Sikhs, Pakistani Muslims and Bangladeshi Muslims [12]. Variations in diets and food choice between the different groups have been observed in surveys conducted in this community [13] with varying degrees of acculturation with migration.

The food frequency questionnaire (FFQ) is often the method of choice in epidemiological studies of diet and chronic diseases [14] because of its ability to estimate long-term usual intake, its ease of use, its relative inexpense and, hence, its applicability to large numbers of people. FFQs can also be easily adapted for studies of the long-term dietary intake of multiethnic populations as specific foods can be included in the list to make the instrument more sensitive to the eating patterns of the study populations. Reports of valid FFQs in South Asians in the UK are, however, lacking. An FFQ, reflecting the diversity of food intake in this community, was specifically designed to measure long-term dietary intake in South Asian women in the UK to use in a population-based case-control study of diet and breast cancer [15]. In this paper, we report the results of the validation of this FFQ using monthly 24-hour recalls collected over one year as the 'silver' standard.

\section{Methods}

Validation of the FFQ was conducted among a sub-sample of 100 healthy South Asian migrant women taking part as controls in a population-based case-control study of breast cancer [16]. Potential controls were identified from general practitioners' patient lists in the Thames and West Midlands regions, which cover some of the areas in the UK with the largest numbers of residents of South Asian origin $[1,17]$. A random sample of these women was then contacted and those agreeing to participate $(76 \%)$ interviewed at home. At the end of the interview, participants were asked if information about their food intake during a previous 24-hour period could be collected over the telephone, once every month, for at least twelve months. At the end of this period they were visited again to complete the FFQ. Ethical approval was obtained from all the relevant ethical committees.
Assuming a true correlation coefficient of about 0.60 between the levels of dietary intake estimated by the 24hour recalls and those estimated by the FFQ, $80 \%$ power and $5 \%$ significance level, a sample of about 100 women was required to ensure that the lower limit of the $95 \%$ confidence interval of the observed correlation coefficient was at least 0.40 [18].

\section{Development and administration of the FFQ}

The development of this FFQ has been described in detail [15]. In short, food sources of energy and macro-nutrients were identified from previous surveys on frequency of food consumption and from weighed intake studies [19] conducted among different sub-groups within the South Asian community in the UK. Foods and composite dishes were included in the FFQ if they were consumed once a week by at least $20 \%$ of the subjects in the food consumption surveys [15]. A total of 207 food items were included in the FFQ because of the wide diversity of diet of the various South Asian communities. This list comprised "natural" foods, such as fruit and various staples, and composite dishes, including 11 South Asian traditional composite dishes for meat, 18 for vegetables and 17 for pulses.

Participants were asked to identify portion of main foods or composite dishes consumed from eight colour photographs representing different portion sizes based on a validated food atlas $[20,21]$. Portion sizes for single items, such as a slice of bread, or less commonly eaten foods were obtained from published sources [22, 23]. Frequency of consumption was obtained by asking open-ended questions on how often a particular food item was eaten per day/week/month or never in the last year. Open-ended questions were easier to ask in an interviewer-administered questionnaire than close-ended questions. They have also been shown to provide more accurate information [24]. For seasonal foods, such as mangoes, women were asked to estimate their average intake when the food was in season. The FFQ was administered by a single interviewer who was familiar with the most commonly spoken South Asian languages. After completing the interview, participants were asked if any food items they consumed regularly were missing from the FFQ. Administration of the FFQ took about 20-30 minutes.

Nutrient intakes were computed on the basis of the frequency of consumption of each unit of food and nutrient content of the specified portions. The composition of the South Asian foods was mostly obtained from food tables especially compiled for South Asian diets in the UK [25]. All the recipes in these food tables had been collected using the precise weighing method during a dietary survey of commonly consumed foods in the various sub-groups of the South Asian community. Mean 
nutrient values of these recipes were calculated from triplicate samples of each recipe. A total of 277 recipes in the nutrient database were used to analyse the FFQ dietary information. Most items [176] in the FFQ corresponded to natural foods or composite dishes with one single recipe. For 31 of the 46 South Asian traditional composite dishes, however, there were three to four different recipes according to region and religious background in South Asia, main type of fat used, and inclusion of onions or tomatoes. For example, one recipe for lamb curry is Pakistani Lamb with onion and tomatoes cooked with ghee, another recipe for the same dish is Pakistani Lamb cooked in corn oil, and a third is Punjabi Mutton without tomatoes cooked in ghee [25]. The recipe closest to a woman's background and/or dietary habits was selected for nutrient analyses of her FFQ data. Nutrient analysis were conducted in the customised computer analysis programme COMP-EAT 5 [26].

\section{"Silver" standard}

Monthly 24-hour recalls were conducted over a 1-year period prior to the administration of the FFQ. A standardised protocol was used to obtain information about foods eaten in a previous 24-hour period over the telephone. Phone calls were not pre-arranged with participants so that they could not predict the day they would be contacted. At the start of the interview, information was obtained about type of milk used in tea and coffee, and, what type of fat was used in preparing recipes, making chapatis and frying foods. Information about food consumption was obtained by asking about foods eaten at meals as well as snacks eaten between meals. Where composite dishes were eaten, information about the main ingredients in the dish was recorded (e.g. type of lentil and fat used). Portion sizes of various foods and composite dishes consumed were obtained using household measures such as tablespoons, serving spoons, bowls and cups. For shop-bought items (e.g. bread), their characteristics (e.g. the size of loaf and thickness of the slice) were obtained as well as their brand names to enable, as far much as possible, a close match with items listed in the UK food tables. A large proportion of recalls was conducted in the subjects' mother tongue. Phone calls were monitored periodically by the senior nutritionist.

A coding manual for the 24-hour recall was developed, which contained portion sizes and codes for South Asian recipes available in the UK Food Tables [27, 28] supplemented by recipes collected by one of the study team members [25]. The most appropriate recipe was selected from this coding manual which contained 350 items. The list of portion sizes published by The UK Ministry for Agriculture, Fisheries and Foods (MAFF)
$[22,23]$ is limited, especially for recipes consumed by South Asian communities. Therefore four team members weighed various meat, vegetable and rice dishes to obtain average weights of tablespoon and servingspoon servings of these dishes. Portion size for each recipe consumed was calculated from the number of tablespoon or serving spoons consumed. Coding of recipes and allocation of portion sizes was conducted independently by two nutritionists for all the 24-hour recalls and any disagreements discussed with the rest of the study team. Nutrient analyses of the 24-hour recalls were carried out using COMP-EAT [26]. Daily nutrient intakes for each woman were computed as the arithmetic mean of the nutrient intakes from her 24-hour recalls.

\section{Statistical methods}

Validation of the FFQ was assessed in terms of its ability to accurately rank individuals according to their nutrient intake, rather than in terms of its ability to accurately estimate absolute levels of nutrient intake. Ranking nutrient intake into quantiles is commonly used in the analysis of epidemiological studies of the relation between diet and chronic diseases. Thus, quartile agreement between the two dietary methods was assessed by calculating the percentage of women classified in the same, the same or adjacent, and in opposite quartiles. Kappa statistics were calculated to assess agreement between quartile classification whilst taking chance agreement into account [29]. Spearman correlation coefficients were also estimated to assess level of agreement between ranked nutrient intakes. Pearson correlation coefficients are provided for comparison with published studies. For energy-adjusted analyses, residuals from a normal errors regression model of the nutrient on total energy intake (both on a logarithmic scale) were used. To correct for within-person day-to-day intake variation in monthly 24-hour recalls, de-attenuated Pearson correlation coefficients were calculated [30]. The effect of a nutrient on disease risk will be attenuated in analytic studies that use this FFQ to estimate dietary intake due to random misclassification. Calibration coefficients to adjust for FFQ misclassification were calculated from a linear regression of 24-hour recall nutrient intake on FFQ nutrient intake [31]. All analyses were conducted using STATA 7.

\section{Results}

Women were asked to take part in the validation study sequentially as they were recruited as healthy controls into the main case-control study until we had 100 women who had completed at least nine 24-hour recalls. 
A total of 133 eligible women were asked; $14 \%$ refused and a further $19 \%$ were lost to follow-up, yielding a $76 \%$ response rate. Women who participated in the validation study were similar to the whole group of randomly selected population-based controls for the case-control study, except that they had a slightly higher BMI and were of a slightly higher social class (Table 1).

The median number of recalls per woman was 13 , with all women having completed at least 9 recalls. The median interval between recalls was 5.5 weeks (range: 4.4 to 9.2 weeks). Of the women $91 \%$ had at least one of their recalls conducted on either a Sunday or a Monday, thus recording part of their weekend dietary intake. Only three $(3 \%)$ women identified one food item each that they consumed regularly but which was not included in the FFQ. These could easily be allocated to an FFQ item with similar ingredients (e.g. Uthapam was not in the FFQ but is similar to Dokra).

Table 2 shows nutrient intakes as estimated by the multiple 24-hour recalls and the FFQ. The 24-hour recalls produced lower mean estimates of absolute intake than the FFQ, particularly for vitamins $C$ and $A$, but the difference between the two methods was smaller after adjustment for energy intake.

The proportion of individuals who were classified by the FFQ and the multiple 24-hour recalls in the same or adjacent quartiles of energy and macro-nutrient intake ranged from $74 \%$ (total energy) to $96 \%$ (protein) (Table 3 ). Similar levels of agreement were observed for micronutrients, ranging from $89 \%$ (vitamin D and folate) to $65 \%$ (Vitamin A). Misclassification into opposite quartiles was very low (0-5\%) for all nutrients except vitamin A (10\%). The kappa statistics showed fair to moderate agreement between the two methods for most nutrients, with the exception of vitamin A. Spearman correlation coefficients between levels of intake estimated by the two methods were good for all nutrients except vitamin $\mathrm{A}$, and for most macro-nutrients they improved after adjustment for energy intake, but not for several micro-nutrients. Energy-adjusted Spearman correlation coefficients ranged from 0.76 (protein) to 0.51 (vitamin B12), except for calcium (0.49), vitamin C (0.46), monounsaturated fat (0.38) and vitamin A (0.17). Energy-adjusted Pearson correlation coefficients were of similar magnitude. De-attenuated Pearson coefficients which took into account within-person variation in monthly 24-hour recalls, improved the correlations between the FFQ and the 24-hour recalls only slightly (Table 3). Similar results were observed for vegetarians and meat-eaters. For instance, the percentage of vegetarians who were classified in the same or adjacent quartiles by the two methods was $69 \%, 90 \%, 90 \%, 96 \%$ and $87 \%$ for total energy, total fat, carbohydrates, proteins and NSP, respectively. The equivalent figures for
Table 1 Representativeness of the sub-sample of 100 women who participated in the validation study

\begin{tabular}{llcc}
\hline & Unit/category & Validation study & $\begin{array}{l}\text { Controls in the } \\
\text { main study } \\
(\mathrm{n}=483)\end{array}$ \\
\hline Age $^{\mathrm{a}}$ & Mean (SD) & $(\mathrm{n}=100)$ & $53.3(9.0)$ \\
Age arrived in the UK & Range & $53.5(8.5)$ & $28-75$ \\
Height & Mean (SD) & $34-75$ & $28.2(10.9)$ \\
Body Mass Indexa (kg/m ${ }^{\mathrm{b}}$ ) & Mean (SD) & $27.5(9.1)$ & $154.4(6.1)$ \\
Formal education & Mean (SD) & $153.4(6.5)$ & $27.8(4.94)$ \\
Literate in English & \% & $29.1(4.81)$ & 83 \\
Literate in mother tongue & \% & 84 & 60 \\
Current household social class & \% & 66 & 84 \\
& Non-manual (\%) & 62 & 53 \\
Ethnic group & Manual (\%) & 35 & 45 \\
& Unclassified (\%) & 3 & 2 \\
& Pakistani Muslim (\%) & 19 & 17 \\
& Gujerati Hindu (\%) & 44 & 22 \\
Punjabi Sikh (\%) & 19 & 6 \\
Vegetarian diet & Bangladeshi Muslim (\%) & 0 & 71 \\
\hline
\end{tabular}

a Measured at the start of the study/first 24 hour recall

b Arithmetic mean and standard deviation (SD)

c Measured as either the social class of the woman or of her partner, whichever was the highest

d Includes work in the armed forces, unemployed and missing information on occupation

e Includes Gujerati Muslims, East African Ismaili Muslims and Bengali Hindus 
Table 2 Absolute nutrient intakes and nutrient densities as estimated by multiple monthly 24-hour recalls and the FFO

\begin{tabular}{|c|c|c|c|c|}
\hline \multirow[t]{2}{*}{ Nutrient } & \multicolumn{2}{|c|}{$\begin{array}{l}\text { Multiple 24-hour recalls } \\
(n=100)\end{array}$} & \multicolumn{2}{|c|}{$\begin{array}{l}\text { FFQ } \\
(n=100)\end{array}$} \\
\hline & Mean $^{\mathrm{a}}$ & $S D^{a}$ & Mean $^{\mathrm{a}}$ & $S D^{a}$ \\
\hline \multicolumn{5}{|l|}{ Absolute intakes } \\
\hline \multicolumn{5}{|l|}{ Macronutrients } \\
\hline Energy (kcal) & 1637.0 & 383.9 & 1990.4 & 504.2 \\
\hline Fat (g) & 69.0 & 20.9 & 88.1 & 30.4 \\
\hline Saturated fat (g) & 21.5 & 7.6 & 26.7 & 9.8 \\
\hline Monounsaturated fat (g) & 18.9 & 6.3 & 26.7 & 9.6 \\
\hline Polyunsaturated fat (g) & 18.9 & 7.6 & 28.0 & 12.9 \\
\hline Cholesterol (mg) & $102^{b}$ & $41,272^{b}$ & $114^{b}$ & $45,270^{\mathrm{b}}$ \\
\hline Carbohydrates (g) & 215 & 49 & 254 & 62 \\
\hline Protein(g) & 53.4 & 14.6 & 61.2 & 17.4 \\
\hline Englyst fibre/NSP (g) & 16.7 & 4.8 & 23.3 & 6.7 \\
\hline \multicolumn{5}{|l|}{ Micronutrients } \\
\hline Vitamin C (mg) & $50.9^{\mathrm{b}}$ & $21.3,120.9^{b}$ & $87.2^{\mathrm{b}}$ & $35.4,202.6^{\mathrm{b}}$ \\
\hline Vitamin $\mathrm{A}$ (retinol equivalents $\mu \mathrm{g}$ ) & $584^{b}$ & $279,1053^{b}$ & $967^{b}$ & $493,2113^{b}$ \\
\hline Calcium (mg) & 759 & 229 & 932 & 301 \\
\hline Vitamin D $(\mu \mathrm{g})$ & $0.76^{b}$ & $0.2,2.1^{\mathrm{b}}$ & $0.92^{\mathrm{b}}$ & $0.2,3.1^{b}$ \\
\hline Iron (mg) & 10.8 & 3.1 & 12.5 & 3.4 \\
\hline Folate $(\mu \mathrm{g})$ & 180 & 50 & 227 & 69 \\
\hline Vitamin B12 $(\mu \mathrm{g})$ & $1.54^{b}$ & $0.7,3.5^{b}$ & $1.70^{\mathrm{b}}$ & $0.8,3.8^{b}$ \\
\hline \multicolumn{5}{|l|}{ Nutrient densities } \\
\hline \multicolumn{5}{|l|}{ Macronutrients } \\
\hline$\%$ energy from fat & 37.5 & 5.4 & 39.3 & 6.4 \\
\hline$\%$ energy from saturated fat & 11.7 & 2.6 & 12.0 & 2.6 \\
\hline$\%$ energy from monounsaturated fat & 10.2 & 1.8 & 11.9 & 2.1 \\
\hline$\%$ energy from polyunsaturated fat & 10.3 & 3.3 & 12.4 & 3.8 \\
\hline Cholesterol (mg/1000kcal) & $63.9^{\mathrm{b}}$ & $30.8,133.2^{b}$ & $59.1^{\mathrm{b}}$ & $27.4,118.6^{b}$ \\
\hline$\%$ energy from carbohydrates & 49.4 & 4.6 & 48.2 & 5.5 \\
\hline$\%$ energy from protein & 13.1 & 2.3 & 12.4 & 2.3 \\
\hline Englyst fibre/NSP (g/1000 kcal) & 10.4 & 2.5 & 11.8 & 2.3 \\
\hline \multicolumn{5}{|l|}{ Micronutrients } \\
\hline Vitamin C (mg/1000kcal) & $32.0^{\mathrm{b}}$ & $12.8,72.8^{\mathrm{b}}$ & $45.2^{\mathrm{b}}$ & $18.2,97.6^{\mathrm{b}}$ \\
\hline Vitamin A (retinol equivalents $\mathrm{g} / 1000 \mathrm{kcal}$ ) & $367^{\mathrm{b}}$ & $208,600^{b}$ & $501^{b}$ & $256,1055^{b}$ \\
\hline Calcium (mg/1000kcal) & 469 & 116 & 474 & 108 \\
\hline Vitamin D ( $\mu \mathrm{g} / 1000 \mathrm{kcal})$ & $0.48^{b}$ & $0.16,1.13^{b}$ & $0.48^{\mathrm{b}}$ & $0.12,1.40^{\mathrm{b}}$ \\
\hline Iron (mg/1000kcal) & 6.63 & 1.37 & 6.31 & 0.94 \\
\hline Folate ( $\mu \mathrm{g} / 1000 \mathrm{kcal})$ & 111.42 & 24.45 & 115.21 & $(27.05)$ \\
\hline Vitamin B12 ( $\mu \mathrm{g} / 1000 \mathrm{kcal})$ & $0.97^{\mathrm{b}}$ & $0.46,2.10^{b}$ & $0.88^{\mathrm{b}}$ & $0.40,1.73^{b}$ \\
\hline
\end{tabular}

Arithmetic mean and standard deviation (SD) unless otherwise specified

b Geometric mean and empirical 5th, 95th centiles meat-eaters were $79 \%, 79 \%, 79 \%, 96 \%$ and $94 \%$, respectively.

Table 4 shows nutrient-specific calibration coefficients that may be used to correct for misclassification introduced by this dietary assessment method. These coefficients were close to, or greater than, 0.50 for nearly all nutrients indicating that the degree of misclassification introduced by the FFQ would be acceptable for most nutrients. Thus, if a relative risk of 1.50 per unit increase in quartile of intake of a given nutrient is observed in an analytical study based on this FFQ the true relative risk, assuming no other sources of bias or confounding, will be 1.72 for protein, 2.70 for monounsaturated fat, and values between these two for all the other nutrients except total energy and vitamin A where the degree of attenuation would be much greater.

\section{Discussion}

The results of this validation study show that this FFQ can provide a good valid assessment of nutrient intake in South Asian populations in the UK, except for vitamin A. The FFQ classified around $80 \%$ or more women into the same or adjacent quartiles of intake as the multiple 24-recalls did for nearly all nutrients, except for vitamin $A$, and energy-adjusted correlation coefficients were mostly over 0.50 . The levels of agreement were generally at the higher end of those found for other FFQ instruments [32-35]. They are comparable to those reported for FFQs used in Western populations $[18,36,37]$ and for those designed for multiethnic populations in Los Angeles [30] and Mexican Americans in Texas [38]. Similar low levels of agreement between 24-hour recalls and 
Table 3 Level of agreement between multiple monthly 24-hour recalls and FFQ in the study population of 100 women

\begin{tabular}{|c|c|c|c|c|c|c|c|c|c|}
\hline \multirow[b]{2}{*}{ Nutrient } & \multicolumn{4}{|c|}{ Level of quartile agreement ${ }^{\mathrm{a}}$} & \multicolumn{3}{|c|}{ Pearson correlation coefficient } & \multicolumn{2}{|c|}{$\begin{array}{l}\text { Spearman correlation } \\
\text { coefficient }\end{array}$} \\
\hline & $\begin{array}{l}\text { Same } \\
\text { quartile (\%) }\end{array}$ & $\begin{array}{l}\text { Same } \pm 1 \\
\text { quartile (\%) }\end{array}$ & $\begin{array}{l}\text { Opposite } \\
\text { quartile (\%) }\end{array}$ & $\begin{array}{l}\text { Kappa } \\
\text { statistics }\end{array}$ & Crude & $\begin{array}{l}\text { Energy } \\
\text { adjusted }^{\text {a }}\end{array}$ & $\begin{array}{l}\text { Deattenuated } \\
\text { energy } \\
\text { adjusted }^{a}\end{array}$ & Crude & $\begin{array}{l}\text { Energy } \\
\text { adjusted }^{\text {a }}\end{array}$ \\
\hline Energy (kcal) & 43 & 74 & 5 & 0.30 & 0.48 & - & - & 0.45 & - \\
\hline Fat (g) & 44 & 85 & 3 & 0.41 & 0.57 & 0.58 & 0.59 & 0.53 & 0.59 \\
\hline Saturated Fat (g) & 43 & 87 & 0 & 0.44 & 0.60 & 0.64 & 0.74 & 0.60 & 0.63 \\
\hline Monounsaturated fat (g) & 46 & 76 & 4 & 0.34 & 0.51 & 0.36 & 0.41 & 0.48 & 0.38 \\
\hline Polyunsaturated fat (g) & 41 & 84 & 3 & 0.38 & 0.57 & 0.54 & 0.60 & 0.52 & 0.54 \\
\hline Cholesterol (mg) & 49 & 91 & 0 & 0.52 & 0.79 & 0.69 & 0.76 & 0.73 & 0.69 \\
\hline Carbohydrates (g) & 48 & 85 & 3 & 0.44 & 0.43 & 0.52 & 0.58 & 0.39 & 0.56 \\
\hline Protein(g) & 50 & 96 & 0 & 0.57 & 0.57 & 0.73 & 0.77 & 0.55 & 0.76 \\
\hline NSP(g) & 53 & 90 & 1 & 0.54 & 0.39 & 0.67 & 0.72 & 0.43 & 0.71 \\
\hline Vitamin C (mg) & 40 & 79 & 5 & 0.31 & 0.45 & 0.48 & 0.54 & 0.40 & 0.46 \\
\hline Vitamin A (retinol equivalents $\mu \mathrm{g}$ ) & 25 & 65 & 10 & 0.04 & 0.41 & 0.24 & 0.30 & 0.18 & 0.17 \\
\hline Calcium (mg) & 43 & 80 & 3 & 0.36 & 0.45 & 0.51 & 0.55 & 0.45 & 0.49 \\
\hline Vitamin D $(\mu \mathrm{g})$ & 51 & 89 & 0 & 0.52 & 0.59 & 0.69 & 0.78 & 0.69 & 0.69 \\
\hline Iron (mg) & 43 & 83 & 0 & 0.41 & 0.37 & 0.55 & 0.60 & 0.36 & 0.58 \\
\hline Folate $(\mu \mathrm{g})$ & 41 & 89 & 0 & 0.44 & 0.49 & 0.68 & 0.77 & 0.44 & 0.70 \\
\hline Vitamin B12( $\mu \mathrm{g})$ & 40 & 81 & 3 & 0.34 & 0.58 & 0.53 & 0.57 & 0.52 & 0.51 \\
\hline
\end{tabular}

a Unit of analysis is residual of each nutrient regressed on energy (both on a logarithmic scale, except for energy)

FFQ estimates of vitamin A intake have also been reported by others $[34,36]$. Vitamin A is found in large quantities in a limited number of foods. 24-hour recalls will inevitably miss days when these foods are eaten whereas the FFQ may overestimate intakes of vitamin A as a result of the large variety of fruit and vegetables listed, recall of usual frequency of intake over a longer period of time and pre-allocation of portion sizes.

The high response rate achieved in the present study $(76 \%)$ is similar to the $76-90 \%$ response rate obtained in a multiethnic US population in Los Angeles [30]. The Los Angeles study subjects were, however, only asked to complete 3 telephone based 24-hour recalls [30]. The response rate is higher than the $15 \%$ seen in some validation studies using weighed intake or food diaries [32], and so more representative of those likely to be included in epidemiological studies of diet and chronic diseases. The distribution of the various South Asian groups in the validation sample closely reflected the overall distribution in the UK [17], except that, due to difficulties in obtaining good translation services, we were unable to include Bangladeshi subjects. They, however, represent only $9 \%$ of all South Asians in the UK [17].

There is no gold standard for the validation of many of the nutrients estimated using FFQs. The 24-hour recall has been widely used as the "silver" standard method in validation studies [30,32,37]. They are easy to use in a population with diverse food patterns and, hence, particularly appropriate to study culturally di- verse groups [30,39]. Multiple 24-hour recalls have also been suggested as an adequate method of validation among populations with lower literacy and motivation [18]. To further encourage motivation we used telephone based 24-hour recalls. Telephone interviews have been shown to provide data comparable to personal interviews with less effort and cost [40].

24-hour recalls have been widely used as the reference method in FFQ validation studies; however, their sources of error may not be independent as both methods rely on recall. To reduce this to a minimum we intentionally made the methods as different as was possible. For the 24-hour recalls all foods eaten were systematically collected on a meal by meal basis over the recent past 24-hours. The most appropriate food/composite dish was selected from all available food tables. Portion size estimation was based on spoon servings. For the FFQ different demands were made. Subjects were asked to estimate how much of each food item in the FFQ they ate, on average, during the previous year which requires use of longer term memory. Portion sizes were mostly ascertained through photographs.

Single 24-hour recalls have been noted to provide surprisingly close levels of agreement with 14-day weighed intake records [32], but they are affected by day-to-day fluctuation in dietary intake [36] resulting in random misclassification of intake and, hence, in attenuation of the level of agreement with the intake estimated by FFQs. In the present study, multiple recalls 
Table 4 Nutrient-specific calibration coefficients estimated from the regression of energy-adjusted multiple 24-hour recall nutrient intake on FFQ nutrient intake

\begin{tabular}{|c|c|c|}
\hline \multirow[t]{2}{*}{ Nutrient } & \multicolumn{2}{|c|}{ Calibration coefficient ${ }^{\mathrm{a}, \mathrm{b}}$} \\
\hline & $\begin{array}{l}\text { Continuous } \\
\text { (per unit } \\
\text { increase) }\end{array}$ & $\begin{array}{l}\text { Quartiles } \\
\text { (per quantile } \\
\text { increase) }\end{array}$ \\
\hline Energy (kcal) & 0.36 & 0.24 \\
\hline Fat (g) & 0.52 & 0.54 \\
\hline Saturated fat (g) & 0.60 & 0.62 \\
\hline Monounsaturated fat (g) & 0.38 & 0.42 \\
\hline Polyunsaturated fat (g) & 0.57 & 0.51 \\
\hline Cholesterol (mg) & 0.63 & 0.69 \\
\hline Carbohydrates (g) & 0.43 & 0.55 \\
\hline Protein(g) & 0.69 & 0.75 \\
\hline $\operatorname{NSP}(g)$ & 0.84 & 0.67 \\
\hline Vitamin C (mg) & 0.45 & 0.41 \\
\hline Vitamin A (retinol equivalents $\mu \mathrm{g}$ ) & 0.19 & 0.08 \\
\hline Calcium (mg) & 0.51 & 0.47 \\
\hline Vitamin D $(\mu \mathrm{g})$ & 0.50 & 0.67 \\
\hline Iron (mg) & 0.69 & 0.57 \\
\hline Folate $(\mu \mathrm{g})$ & 0.60 & 0.63 \\
\hline Vitamin B12 $(\mu \mathrm{g})$ & 0.59 & 0.47 \\
\hline
\end{tabular}

a Energy-adjusted nutrients were calculated as residuals from the regression of the nutrient on total energy intake (both on a logarithmic scale)

b Calibrated relative risk for a given nutrient is equal to exp (logarithm of the observed relative risk/calibration coefficient) which is equivalent to observed relative risk ${ }^{\left(1 / / c^{2} \text { libration coefficient) }\right.}$

were collected over more than one year to reduce intraindividual variation. The number of recalls required in this study to obtain a correlation of at least 0.90 between ranks of mean 24-hour intakes and true ranks of dietary intake were retrospectively calculated [41] to be $7,10,7$, 6 and 8 for energy, fat, protein, carbohydrates and NSP, respectively. The average number of 24 -hour recalls conducted per person was therefore more than sufficient to capture the true ranks of intake of most nutrients. Thus, correction for intra-individual variation by calculating de-attenuated Pearson correlation coefficients [34, 37] improved the correlation between the two methods but only to a small extent as the large number of recalls per subject greatly reduced measurement error.

Although accuracy of absolute levels of nutrient intake (as opposed to accurate ranking) is not necessary to identify diet/disease associations, the levels of absolute nutrient intake obtained by the FFQ in this study were higher than those estimated by the multiple 24 -hour recalls, but the energy-adjusted mean nutrient intakes were comparable. FFQs are known to over-estimate true intake of a number of nutrients [32], probably due to the use of long lists of foods and difficulties in estimating accurate frequency of food consumption and portion sizes. However, validation studies of energy intake from reported diet compared to doubly labelled water measurements of energy expenditure have shown that both 24-hour recalls and FFQs tend to under-estimate true intake $[40,42,43]$.

Relative risks for nutrient-disease associations derived from analytic studies in which dietary intake is estimated by the FFQ will be biased to one due to non-differential misclassification introduced by this dietary assessment method. Nutrient-specific coefficients can be used to re-calibrate the association between dietary intake and disease in analytical studies which use this FFQ to estimate usual intake. The assumption being that the 24-hour recalls represent true intake and are unbiased and uncorrelated with those of the FFQ. Recent papers suggests this may not be so for protein and energy at least where urinary nitrogen excretion and doubly labelled water can be used to represent true intake $[43,44]$. Further work to quantify the correlated errors for nutrients other than protein is needed. Differential under-reporting of intake by multiple $24-\mathrm{hr}$ recalls (the reference method) compared to FFQs may affect the validity of calibrated risk estimates. However the extent of underreporting may not be too severe in this population of older South Asian women as they are more sedentary and therefore have lower energy expenditure than the general population [45]. The calibration coefficients for our FFQ using 24-hour recalls as a marker of true intake compare favourably with those reported by others using the same assumptions [30,37].

In short, this study shows that the validity of this new FFQ specifically developed for use in South Asian women in the UK is comparable to that of other FFQs developed for Western populations. These findings indicate that this FFQ could be a tool to examine the role of diet in the aetiology of chronic diseases in this population.

Acknowledgements We thank Ms. N. Khurana, Ms. R. Kabawala and Ms. D. Lathiga for their clerical support throughout the study and Ms. B. Peachey and Ms. H. Nguyen for their help with the data entry.

Contributors IdSS and PM, the principal investigators, designed and monitored the progress of the study. TKK designed the FFQ with LS and PM. LS supervised the data collection, coding and quality of the 24-hour recall data. DB conducted the FFQ interviews and the first coding and entering of the 24 -hour recall data. $\mathrm{VMcC}$ conducted all the statistical analyses. LS and PM took the lead in writing the paper. All authors contributed to the interpretation of the results and to the final draft of the paper. 


\section{References}

1. Karn V (1996) Ethnicity in 1991 Census Volume 3. Social geography and ethnicity in Britain: geographical spread, spatial concentration and internal migration. London: HMSO

2. McKeigue PM, Ferrie JE, Pierpoint T, Marmot MG (1993) Association of early-onset coronary heart disease in South Asian men with glucose intolerance and hyperinsulinemia. Circulation $87: 152-160$

3. Balarajan R, Adelstein AM, Bulusu L, Shukla V (1984). Patterns of mortality among migrants to England and Wales from the Indian subcontinent. Br Med J 289:1185-1187

4. Pedoe HTT, Clayton D, Morris JN, Brigden W, McDonald L (1975) Coronary heart attacks in East London. Lancet 2: 833-838

5. Donaldson LJ, Taylor JB (1983) Patterns of Asian and non-Asian morbidity in hospitals. Br Med J 286:949-951

6. McKeigue PM, Pierpoint T, Ferrie JE, Marmot MG (1992) Relationship of glucose intolerance and hyperinsulinaemia to body fat pattern in South Asians and Europeans. Diabetologia 35: 785-791

7. Marmot MG, Adelstein AM, Bulusu L (1984) Immigrant mortality in England and Wales 1970-78. Causes of death by country of birth. Studies on Medical and Population subjects no 47. London: HMSO

8. Matheson LM, Dunnigan MG, Hole D, Gillis CR (1990) Incidence of colo-rectal, breast and lung cancer in a Scottish Asian population. Health Bull 43(5): 245-249

9. Marmot MG, Adelstein AM, Bulusu L (1984) Immigrant Mortality in England and Wales 1970-78. Studies on Medical and Population Sciences no.47. London: HMSO

10. Leslie C, Young A (1992) Paths to Asian Medical Knowledge. San-Francisco: University of California Press

11. Fieldhouse P (1986) Food \& Nutrition: Customs \& Culture. London: Croom Helm

12. Modood T, Berthoud R, Lakey J, Nazroo J, Smith P, Virdee S et al. (1997) Ethnic Minorities in Britain. London: Policy Studies Institute

13. Kassam-Khamis T, Judd PA, Thomas JE, Sevak L, Reddy S, Ganatra S (1995) Frequency of consumption and nutrient composition of composite dishes commonly consumed by South Asians originating from Gujerat and the Punjab. J Hum Nutr Diet 8:265-277
14. Willett WC, Sampson L, Browne ML, Stampher MJ, Rosner B, Hennekens CH et al. (1988) The use of a self-administered questionnaire to assess diet four years in the past. Am J Epidemiol 127: 188-199

15. Kassam-Khamis T, Nanchahal K, Mangtani P, dos Santos Silva I, McMichael A, Anderson A (1999) Development of an interview-administered food-frequency questionnaire for use amongst women of South Asian ethnic origin in Britain. J Hum Nutr Diet 12:7-12

16. dos Santos Silva I, Mangtani P, McCormack V, Bhakta D, Sevak L, McMichael AJ (2002) Life long vegetarianism and risk of breast cancer: a populationbased case-control study among South Asian migrant women living in England. Int J Cancer 99:238-244

17. Peach C (1996) Ethnicity in the 1991 Census. Volume 2. The Ethnic Minority Populations of Great Britain. London: HMSO

18. Willett W (1990) Nutritional Epidemiology. New York: Oxford University Press

19. Kassam-Khamis T, Judd PA, Thomas JE, Sevak L, Reddy S, Ganatra S (1995) Frequency of consumption and nutrient composition of composite dishes commonly consumed by South Asians originating from Gujerat and the Punjab. J Hum Nutr Diet 8:265-277

20. Nelson M, Atkinson M, Darbyshire S (1994) Food photography I: the perception of food portion size from photographs. Br J Nutr 72:649-663

21. Nelson M, Atkinson M, Darbyshire $S$ (1996) Food photography II; use of food photographs for estimating portion size and the nutrient content of meals. Br J Nutr 76:31-49

22. Ministry of Agriculture Fisheries and Foods (1994) Food portion sizes. $2^{\text {nd }}$ Ed. London: HMSO

23. Gregory J, Foster K, Tyler H, Wiseman M (1990) The dietary and nutritional survey of British adults. London: HMSO

24. Tylavsky FA, Sharp GB (1995) Misclassification of nutrient and energy intake from use of closed-ended questions in epidemiological research. Am J Epidemiol 142:342-352

25. Judd P, Kassam-Khamis T, Thomas JE (2000) The Composition and Nutrient Content of Foods Commonly Consumed by South Asians in the UK. London: The Agha Khan Health Board for the United Kingdom

26. COMP-EAT 5 (1998) COMP-EAT version 5, Nutrition Systems, London
27. Holland B, Welch AA, Unwin ID, Buss DH, Paul AA, Southgate DAT (1995) McCance and Widdowson's The composition of foods. 5ed. Cambridge: Royal Society of Chemistry

28. Holland B, Welch AA, Buss DH (1996) Vegetable dishes. The second supplement to McCance and Widdowson's The composition of foods ( $5^{\text {th }}$ Edition). Cambridge: Royal Society of Chemists

29. Armitage P, Berry G, Mathews JNS (2001) Statistical methods in medical research. $4^{\text {th }}$ ed. Malden, MA: Blackwell Science

30. Stram DO, Hankin JH, Wilkins EW, Pike MC, Monroe R, Park S et al. (2000) Calibration of the dietary questionnaire for a multiethnic cohort in Hawaii and Los Angeles. Am J Epidemiol 151:358-359

31. Rosner B, Willett WC, Spiegelman DL (1989) Correction of logistic regression relative risk estimates and confidence intervals for systematic within-person measurement errors. Stats Med 8: 1051-1069

32. Bingham SA, Gill C, Welch A, Day K, Cassidy A, Khaw KT et al. (1994) Comparison of dietary assessment methods in nutritional epidemiology: weighed records v. $24 \mathrm{~h}$ recalls, food-frequency questionnaires and estimated-diet records. Br J Nutr 72:619-643

33. Willett WC, Sampson L, Stampfer MJ, Rosner B, Bain C, Witschi J et al. (1985) Reproducibility and validity of a semiquantitative food frequency questionnaire. Am J Epidemiol 122:51-65

34. Margetts BM, Cade JE, Osmond C (1989) Comparison of a food frequency questionnaire with a diet record. Int J Epidemiol 18:868-873

35. Tjonneland AT, Haraldsdottir J, Overad K, Stripp C, Ewertz M, Jensen OM (1992) Influence of individually estimated portion size on the validity of a semiquantative food frequency questionnaire. Int J Epidemiol 21:770-777

36. Block G, Thompson FE, Hartman AM, Larkin FA, Guire KE (1992) Comparison of two dietary questionnaires validated against multiple dietary records collected during a 1-year period. J Am Diet Assoc 92:686-693

37. Subar AF, Thompson FA, Kipnis V, Midthune D, Hurwitz P, McNutt S et al. (2001) Comparative validation of the Block, Willett, and the National Cancer Institute Food Frequency Questionnaires. Am J Epidemiol 154:1089-1099

38. McPherson SR, Kohl HW, Garcia G, Nichaman MZ, Hanis CL (1995) Foodfrequency questionnaire validation among Mexican-Americans: Starr County, Texas. Ann Epidemiol 5: 378-385 
39. Gnardellis C, Trichopoulou A, Katsouyanni K, Polychronopoulos E, Rimm EB, Trichopoulos D (1995) Reproducibility and validity of an extensive semiquantitative FFQ among Greek school teachers. Epidemiol 6:74-77

40. Tran KM, Johnson RK, Soultanakis RP, Mathews DE (2000) In-person vs telephone-administered multiple-pass 24hour recalls in women: validation with doubly labelled water. J Am Diet Assoc 100:777-780

41. Nelson M, Black AE, Morris JA, Cole TJ (1989) Between- and within subject variation in nutrient intake from infancy to old age: estimating the number of days required to rank dietary intakes with desired precision. Am J Clin Nutr 50:155-167
42. Hill RJ, Davies PS (2001) The validity of self-reported energy intake as determined using the doubly labelled water technique. Br J Nutr 85:415-430

43. Kroke A, Klipstein-Grobusch K, Voss S, Moseneder J, Thielecke F, Noack R et al. (1999) Validation of a self administered food-frequency questionnaire administered in the European Prospective Investigation into Cancer and Nutrition (EPIC) study: comparison of energy, protein and macronutrient intakes estimated with the doubly labelled water, urinary nitrogen and repeated $24-\mathrm{h}$ dietary recall methods. Am J Clin Nutr 70:439-447
44. Kipnis V, Midthune D, Freedman LS, Bingham SA, Schatzkin A, Subar AF et al. (2001) Empirial evidence of correlated biases in dietary assessment instruments and its implications. Am J Epidemiol 153:394-403

45. McCormack VA, Mangtani P, Bhakta D, McMichael AJ, dos Santos Silva I (2003) Heterogeneity of breast cancer risk within the South Asian female population in England: a population-based case-control study of first generation migrants. $\mathrm{Br} \mathrm{J}$ Cancer (in print) 